\begin{tabular}{|c|c|}
\hline Title & $\begin{array}{l}\text { Synthesis of 2-alkyl-2-boryl-substituted-tetrahy drofurans via copper(i)-cataly sed borylative cy clization of aliphatic } \\
\text { ketones }\end{array}$ \\
\hline Author(s) & Kubota, Koji; U esugi, Minami; Osaki, Shun; Ito, Hajime \\
\hline Citation & $\begin{array}{l}\text { Organic \& biomolecular chemistry, 17(23), 5680-5683 } \\
\text { https://doi.org/10.1039/c9ob00962k }\end{array}$ \\
\hline Issue Date & 2019-06-21 \\
\hline Doc URL & http:/hdl. handle.net/2115/8636 \\
\hline Type & article (author version) \\
\hline File Information & manuscript(Org. Biomol. Chem.).pdf \\
\hline
\end{tabular}

Instructions for use 


\section{Synthesis of 2-alkyl-2-boryl-substituted-tetrahydrofurans via copper(I)-catalysed borylative cyclization of aliphatic ketones}

Received 00th January 20xx,

Koji Kubota, ${ }^{a, b}$ Minami Uesugi, ${ }^{b}$ Shun Osaki ${ }^{b}$ and Hajime Ito*a,b

Accepted 00th January 20xx

DOI: 10.1039/x0xx00000x

A new method was developed for synthesizing 2-alkyl-2-boryltetrahydrofuran derivatives from aliphatic ketones using a copper(I)/N-heterocyclic carbene complex catalyst. This reaction presumably proceeds through the nucleophilic addition of a borylcopper(I) intermediate to ketone, followed by intramolecular substitution of the resulting alkoxide for the halide leaving group. The new borylation products, 2-alkyl-2boryl-tetrahydrofuran derivatives with a condensed structure around the C-B bond, cannot be synthesized by other methods.

Tetrahydrofuran scaffolds are important structural motifs frequently found in various bioactive natural products and pharmaceutical drugs. ${ }^{1}$ Despite significant advances toward the development of synthetic approaches capable of providing access to these molecules, the development of a mild and efficient protocol remains highly desired. ${ }^{2}$ Organoboron compounds are useful building blocks in synthetic chemistry as they can be readily converted into various functional groups. ${ }^{3}$ Additionally, their modulable reactivity and good stability toward air and moisture play important roles in their transformations, which highlights their practical utility. ${ }^{3}$ Considering these features, organoboronates with an oxygen-containing cyclic scaffold such as tetrahydrofuran represent promising intermediates for preparing various bioactive molecules and pharmaceutical drugs. However, few methods for synthesising such organoboron compounds are currently available. ${ }^{4}$

Clark et al. and our group independently reported the copper(I)/ $N$-heterocyclic carbene complex-catalysed nucleophilic borylation of aliphatic ketones to give the corresponding $\alpha$-oxygensubstituted organoboronates (Scheme $1 \mathrm{a}$ and $1 \mathrm{~b}$ ). ${ }^{5,6}$ This reaction proceeds through the nucleophilic addition of a borylcopper $(I)$ active species to a $\mathrm{C}=\mathrm{O}$ double bond in ketones to form the copper(I) alkoxide intermediate. Inspired by the reaction mechanism, we questioned whether this copper(I) alkoxide could be used for

\footnotetext{
a. Institute for Chemical Reaction Design and Discovery (WPI-ICReDD), Hokkaido University, Sapporo, Hokkaido, Japan.

b. Division of Applied Chemistry and Frontier Chemistry Center, Faculty of

Engineering, Hokkaido University, Sapporo, Hokkaido, Japan.
}

Electronic Supplementary Information (ESI) available: See DOI: 10.1039/x0xx00000x intramolecular nucleophilic substitution to provide an efficient route to the 2-alkyl-borylsubstituted-tetrahydrofurans, which cannot be synthesized by other methods (Scheme 1c). ${ }^{4}$ The key to developing this borylative cyclization of ketones is controlling chemoselectivity because a borylcopper(I) intermediate can react with the halide functional group to afford the corresponding boryl substitution product through a radical-related mechanism. ${ }^{7-10}$

a. Copper(I)-catalyzed diborylation of ketone reported by Clark et al.

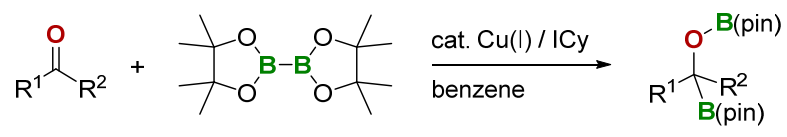

b. Copper(I)-catalyzed protoborylation of ketone reported by our group

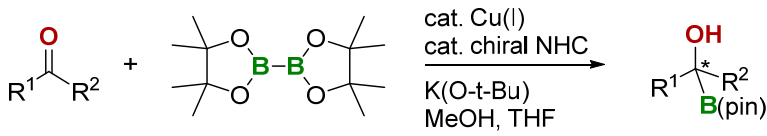

c. Copper(l)-catalyzed borylative cyclization of ketone (This work)

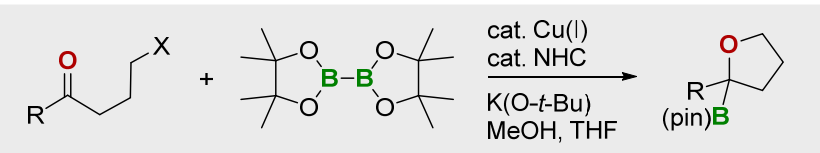

$$
\text { Possible mechanism }
$$

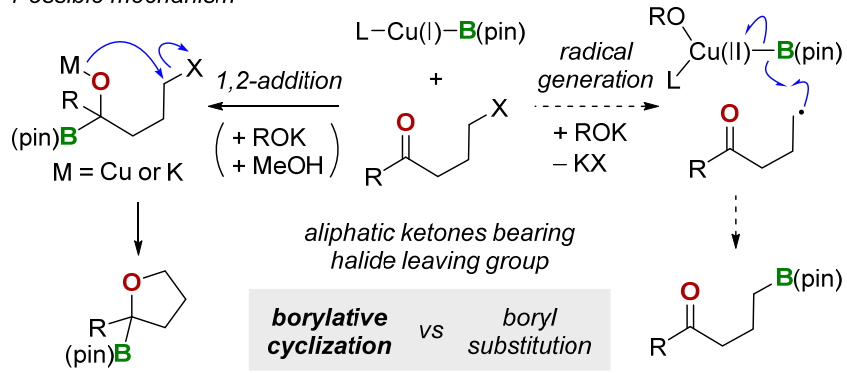

Scheme 1. Copper(I)-catalysed borylation of ketones

Based on our working hypothesis, we investigated the reaction of aliphatic ketone $1 \mathrm{a}$, which bears a chloro group as a leaving group, with a diboron compound $\mathbf{2}$ in the presence of $5 \mathrm{~mol} \% \mathrm{CuCl}, 5 \mathrm{~mol} \%$ imidazolium salts, and a stoichiometric amount of $\mathrm{K}(\mathrm{O}-\mathrm{t}-\mathrm{Bu})$ in tetrahydrofuran (THF) at $30{ }^{\circ} \mathrm{C}$ (Table 1). Pleasingly, the borylative 
cyclization of ketone $1 \mathrm{a}$ in the presence of a copper(I)/ItBu (ItBu・HBF 4 : 1.3-di-tert-butylimidazolium tetrafluoroborate) (L1) complex catalyst proceeded efficiently to afford the desired 2-borylsubstituted-tetrahydrofuran $\mathbf{3 a}$ in good yield with excellent cyclization/substitution selectivity $(\mathbf{3 a} / \mathbf{4 a}=>95: 5)$ (entry 1$)$. Product 3a could not be synthesized by the known $\mathrm{C}-\mathrm{H}$ borylation approach of tetrahydrofurans. ${ }^{4}$ Other imidazolium salts such as 1,3-di-(1adamantyl)-imidazolium tetrafluoroborate $\left(\mathrm{IAd} \bullet \mathrm{HBF}_{4}\right)$ (L2), 1,3dicyclohexylimidazolium chloride $(\mathrm{ICy} \bullet \mathrm{HCl})(\mathbf{L} 3)$ gave lower $3 a$ yields (entries 2 and 3). The reaction using imidazolium salts that bear aromatic substituents on the nitrogen such as 1,3dimesitylimidazolium chloride (IMes $\bullet H C l) \quad$ (L4), 1,3-bis(2,6diisopropylphenyl)imidazolium chloride (IPr $\bullet$ HCI) (L5) afforded poor results (entries 4 and 5 ). We further tested imidazolinium salts such as 1,3-di(1-adamantyl)-imidazolinium tetrafluoroborate $\left(\mathrm{SIAd}_{\bullet} \mathrm{HBF}_{4}\right)$ (L6), 1,3-dimesitylimidazolinium chloride (SIMes・HCl) (L7) and 1,3bis(2,6-diisopropylphenyl)imidazolinium chloride (SIPr $\bullet \mathrm{HCl}$ ) (L8), which gave lower $\mathbf{3 a}$ yields (entries 6-8). We also conducted the reaction using phosphine ligands such as Xantphos ${ }^{8,11}$, which provided the desired product in moderate yield (entry 9).

Table 1. Optimisation of the reaction conditions ${ }^{a}$

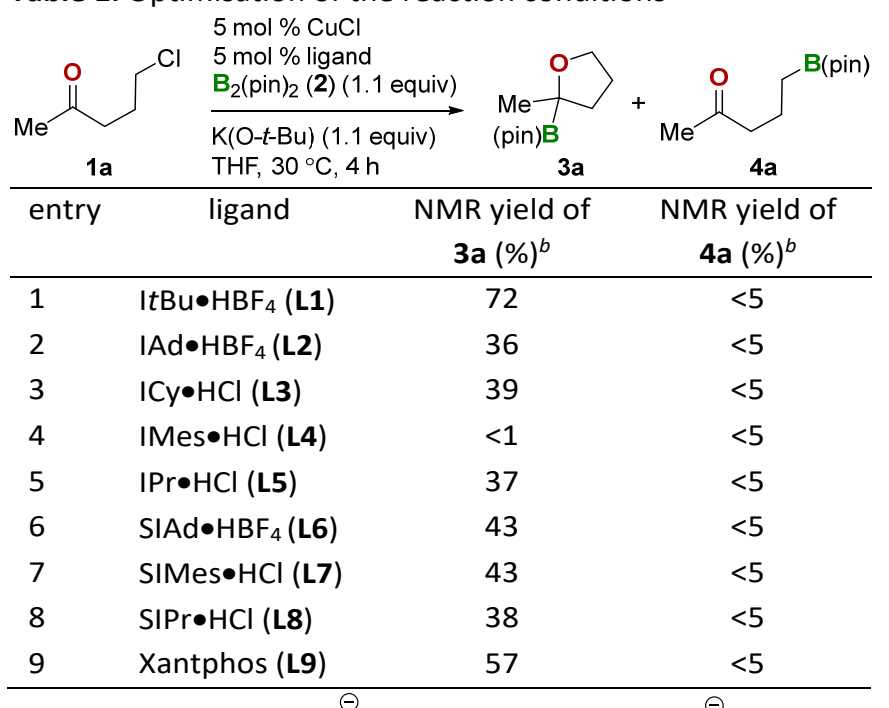

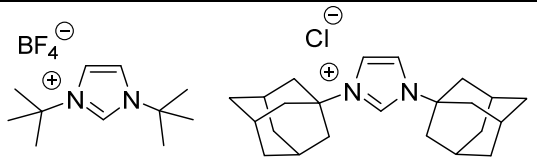

L1<smiles>Cn1cc(Cl)c(Cl)n1</smiles>

L2

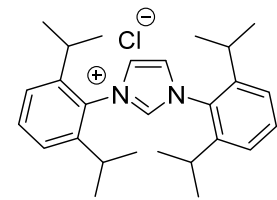

L5<smiles>CN1CN(C)C(Cl)(Cl)C1</smiles>

L7

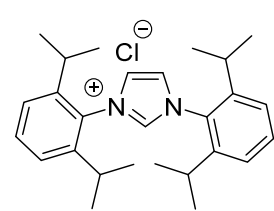

L8

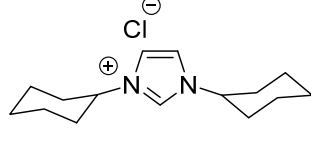

L3

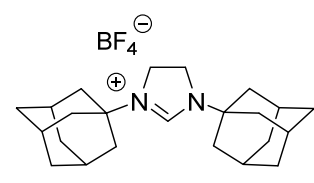

L6<smiles>CC1(C)c2cccc(-c3ccccc3)c2Oc2c(-c3ccccc3)cccc21</smiles>

L9
${ }^{a}$ Conditions: 1a $(0.5 \mathrm{mmol}), \mathrm{CuCl}(0.025 \mathrm{mmol})$, ligand $(0.025$ $\mathrm{mmol})$, bis(pinacolato)diboron 2 (0.55 mmol), K(O-t-Bu) (0.55 $\mathrm{mmol})$ in THF (1.0 mL).

We next investigated the borylative cyclization of $\mathbf{1 b}$ in the presence of a copper(I)/ItBu complex catalyst (Scheme 2). However, the product yield was very low (22\% NMR) under optimized conditions because of formation of byproducts ( $5 \mathbf{b}$ and $\mathbf{6 b}$ ) that derived from the corresponding enolate. We hypothesized that adding an alcohol could trap the copper alkoxide generated from the borylcupration of ketone to suppress the formation of these byproducts and accelerate the catalytic cycle and conversion rate of ketone $\mathbf{1 b} .^{12}$ The generated $\alpha$-hydroxyboronate would then undergo $\mathrm{K}(\mathrm{O}-\mathrm{t}$-Bu)mediated cyclization to give cyclization product $\mathbf{3 b}$. Based on this hypothesis, $\mathrm{MeOH}$ was added to the reaction mixture (Scheme 2). As we anticipated, the reaction proceeded smoothly to afford the desired product $\mathbf{3 b}$ in high yield $(61 \%$ NMR). Notably, only a small amount of $5 \mathbf{b}$ ( $6 \%$ NMR) was detected under modified conditions.

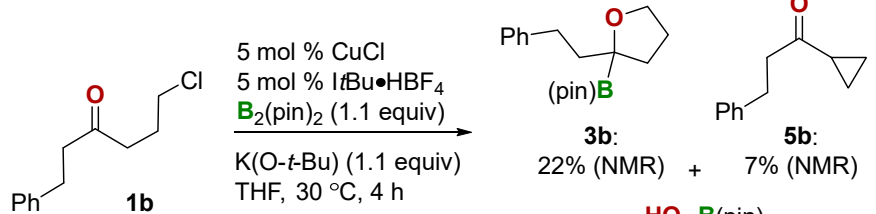

$5 \mathrm{~mol} \% \mathrm{CuCl}$

$5 \mathrm{~mol} \% \mathrm{ltBu} \bullet \mathrm{HBF}_{4}$

$\mathrm{B}_{2}(\text { pin })_{2}$ (1.1 equiv)

MeOH (2.0 equiv)

$\mathrm{K}(\mathrm{O}-t-\mathrm{Bu})$ (1.1 equiv)
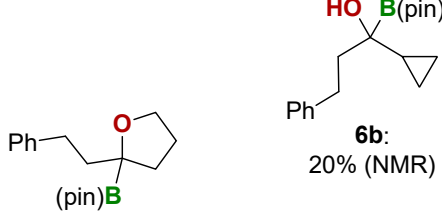

$20 \%($ NMR)

5b: $6 \%$ (NMR)

6b: not detected

Scheme 2. Copper(I)-catalysed borylative cyclisation of ketone $\mathbf{1 b}$

We next investigated the effect of a leaving group (Scheme 3 ). The desired product $\mathbf{3 b}$ was exclusively produced from $\mathbf{1 b}$ in good yield $(61 \%)$ with excellent cyclization/substitution selectivity (3b/4b $=>99: 1)$. Alkyl bromide (1c) and iodide (1d), which are more reactive substrates to boryl substitution reaction than chloride ${ }^{7}$, were converted into an isomeric mixture of $\mathbf{3 b}$ and $\mathbf{4 b}$. When the reaction of alkyl tosylate $(\mathbf{1} \mathbf{e})^{13}$ was conducted, the cyclization selectively proceeded even though the yield was low. These results suggest that the careful choice of a leaving group is needed to achieve high cyclization/substitution selectivity.

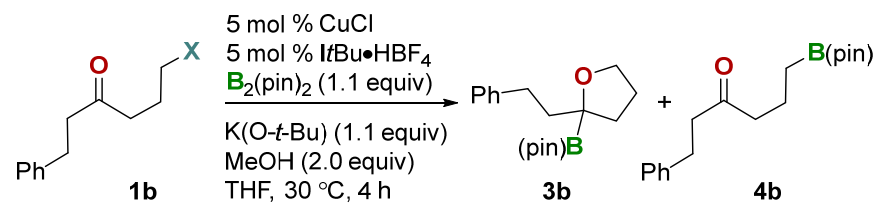

$X=\mathrm{Cl}$ (1b): $61 \%$ (NMR), $\mathbf{3 b} / \mathbf{4} \mathbf{b}=>95: 5$ $\mathrm{Br}$ (1c): $79 \%(\mathrm{NMR}), \mathbf{3 b} / \mathbf{4 b}=\mathbf{b}=\mathbf{5 1}$ I (1d): $77 \%$ (NMR), 3b/4b = 5:95

OTs (1e): $20 \%$ (NMR), $\mathbf{3 b} / \mathbf{4 b}=>95: 5$

Scheme 3. Effect of the leaving group 
With the optimized conditions in hand, the synthesis of various 2-boryl-substituted-tetrahydrofuran derivatives was investigated (Table 2). The reactions of simple aliphatic substrates (1a, $\mathbf{1 b}, \mathbf{1} \mathbf{f}$ and 1g) proceeded smoothly to give the corresponding 2-borylsubstituted-tetrahydrofurans (3a, $\mathbf{3} \mathbf{b}, \mathbf{3} \mathbf{f}$ and $\mathbf{3 g}$ ) in good yields. Fluorine-containing substrates $(\mathbf{1} \mathbf{h}-\mathbf{1 j})$ were also reacted with diboron compound $\mathbf{2}$ to give the desired products (3h-3j) in good to high yields.

Table 2. Substrate Scope ${ }^{a}$

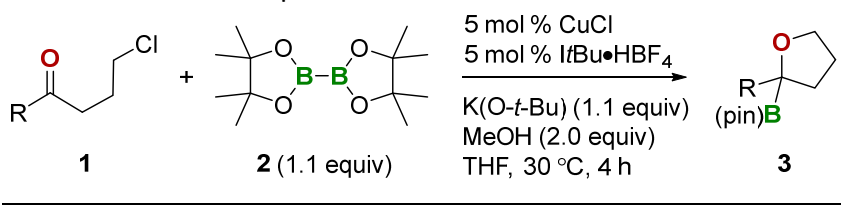

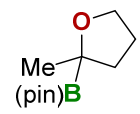

3a $72 \%$ (NMR) $62 \%$ (isolated)<smiles>[18OH]C1(CCc2ccccc2)CCCO1</smiles>

$3 b$ $61 \%$ (NMR) $54 \%$ (isolated)

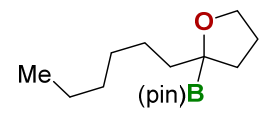

$3 \mathbf{f}$

$43 \%$ (NMR) $36 \%$ (isolated)<smiles>Cc1ccc(CC[C@@]2([18O])CCCO2)cc1</smiles>

$3 g$ 65\% (NMR) $59 \%$ (isolated)<smiles>[18OH]C1(CCc2cccc(C(F)(F)F)c2)CCCO1</smiles>
$3 i$ $76 \%$ (NMR) $63 \%$ (isolated)<smiles>[18OH]C1(CCc2ccc(C(F)(F)F)cc2)CCCO1</smiles>

$3 \mathrm{~h}$ $57 \%$ (NMR) $46 \%$ (isolated)

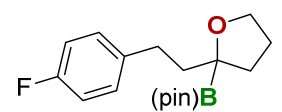

3j

$74 \%$ (NMR)

$47 \%$ (isolated)

${ }^{a}$ Conditions: 1 (0.5 mmol), $\mathrm{CuCl}(0.025 \mathrm{mmol})$, ligand $(0.025 \mathrm{mmol})$, bis(pinacolato)diboron 2 (0.55 mmol), $\mathrm{K}(\mathrm{O}-\mathrm{t}-\mathrm{Bu})(0.55 \mathrm{mmol})$ in THF $(1.0 \mathrm{~mL})$.

The borylative cyclization products could be a useful synthetic block for preparing 2-substituted-tetrahydrofuran derivatives. We conducted a preliminary investigation of the derivatization of the obtained products (Scheme 4). Product 3a was successfully converted into the corresponding trifluoroborate $\mathbf{7}$ through treatment with $\mathrm{KHF}_{2}$ in good yield (69\%). The Aggarwal crosscoupling reaction ${ }^{14}$ of the borylative cyclization product $\mathbf{3 b}$ with benzofuran proceeded to afford the arylated tetrahydofuran $\mathbf{8}$.

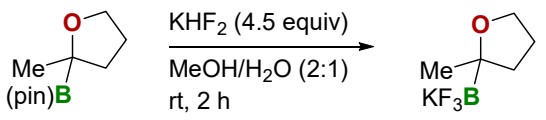

$$
\begin{aligned}
& 3 a \\
& 69 \% \text { (isolated) }
\end{aligned}
$$

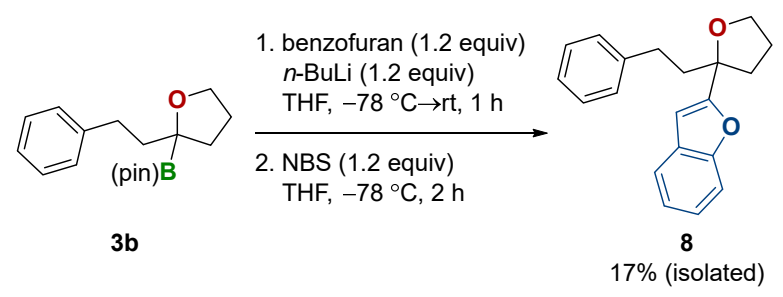

Scheme 4. Derivatization of the borylative cyclization products

To gain insight into the reaction mechanism, we conducted a control experiment (Scheme 5). The mixture of 4-phenylbutan-2-one (9) and (2-chloroethyl)benzene (10) was subjected to the copper(I)catalysed borylative cyclization reaction. Consequently, ketone 9 was selectively reacted with $\mathbf{2}$ to give the 1,2-boryl addition product $\mathbf{1 1}$ in $60 \%$ NMR yield. Conversely, the corresponding boryl substitution product $\mathbf{1 2}$ was not detected and alkyl chloride $\mathbf{1 0}$ was recovered $(80 \%)$ after the reaction. This result suggests that the reactivity of the borylcopper intermediate to ketone functionality is larger than that to alkyl halides under this reaction condition. The borylative cyclization presumably proceeds through the nucleophilic addition of a borylcopper(I) active species to ketone, followed by the intramolecular substitution of the resulting alkoxide for the halide leaving group.<smiles>CC(=O)CCc1ccccc1</smiles>

10 (1.0 equiv)
$5 \mathrm{~mol} \% \mathrm{CuCl}$ $5 \mathrm{~mol}^{\%} \mathrm{ItBu} \bullet \mathrm{HBF}_{4}$ $\mathrm{B}_{2}$ (pin) $)_{2}$ (1.1 equiv) $\mathrm{K}(\mathrm{O}-\mathrm{t}-\mathrm{Bu})(1.1$ equiv) $\mathrm{MeOH}(2.0$ equiv) $\mathrm{THF}, 30^{\circ} \mathrm{C}, 4 \mathrm{~h}$<smiles>CC(O)(Br)CCc1ccccc1</smiles>

10: $80 \%$ recovery

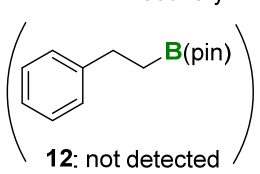

Scheme 5. Mechanistic study.

In conclusion, we have developed a copper(I)-catalysed borylative cyclization of aliphatic ketones for preparing 2-alkylboryl-substituted-tetrahydrofurans, which cannot be synthesized by other methods. A careful choice of the ligand and leaving group was crucial to develop the present transformation with high selectivity. Based on the preliminary mechanistic study, this reaction presumably proceeds through the nucleophilic addition of a borylcopper(I) intermediate to ketone, followed by the intramolecular substitution of the resulting alkoxide for the halide leaving group. We are currently working on the synthesis of oxetane derivatives through the borylative cyclization reaction and further derivatization of the borylation products for efficient synthesis of bioactive compounds and natural products through boron functionalization processes. 


\section{Conflicts of interest}

There are no conflicts to declare.

\section{Acknowledgements}

This work was financially supported by the Japan Society for the Promotion of Science (JSPS) via KAKENHI grants JP18H03907, JP17H06370, JP19K15547 and by the Institute for Chemical Reaction Design and Discovery (ICReDD), which has been established by the World Premier International Research Initiative (WPI), MEXT, Japan.

\section{Notes and references}

1 (a) A. K. Ghosh, P. R. Sridhar, N. Kumaragurubaran, Y. Koh, I. T. Weber, H. Mitsuya, ChemMedChem., 2006, 1, 939; (b) M. D. Delost, D. T. Smith, B. J. Anderson, J. T. Njardarson, J. Med. Chem., 2018, 61, 10996; (c) X. Bai, Z. Yang, M. Zhu, B. Dong, L. Zhou, G. Zhang, J. Wang, Y. Wang, Eur. J. Med. Chem., 2017, 137, 30; (d) T. L. B. Boivin, Tetrahedron Lett., 1987, 43, 3309.

2 The selected examples for synthetic approaches capable of providing access to substituted tetrahydrofurans, see: (a) K. C. Nicolau, C. V. C. Prasad, P. K. Somers, C.-K. Hwang, J. Am. Chem. Soc., 1989, 111, 5330; (b) J. S. Panek, M. Yang, J. Am. Chem. Soc., 1991, 113, 9868; (c) T. A. Grese, K. D. Hutchinson, L. E. Overman, J. Org. Chem., 1993, 58, 2468; (d) M. F. Semmelhack, N. Zhang, J. Org. Chem., 1989, 54, 4483; (e) T.-P. Loh, Q.-Y. Hu, L.-T. Ma, J. Am. Chem. Soc., 2001, 123, 2450; (f) H. M. L. Davies, T. Hansen, M. R. Churchill, J. Am. Chem. Soc. 2000, 122, 3063; (g) L. Vares, T. Rein, Org. Lett., 2000, 2, 2611; (h) B. Ye, J. Zhao, J. M. Mckenna, F. D. Toste, J. Am. Chem. Soc., 2018, 140, 8350 .

3 (a) Boronic Acids: Preparation and Applications in Organic Synthesis, Medicine and Materials, ed. D. G. Hall, Wiley-VCH Verlag GmbH \& Co. KGaA, Weinheim, 2011; (b) N. Miyaura, A. Suzuki, Chem. Rev., 1995, 95, 2357; (c) S. Hara, H. Shudoh, S. Ishimura, A. Suzuki, Bull. Chem. Soc. Jpn., 1998, 71, 2403.

4 The examples for the synthesis of tetrahydrofurans bearing a boryl group, see: (a) C. W. Liskey, J. F. Hartwig, J. Am. Chem. Soc., 2012, 134, 12422; (b) T. Ohmura, T. Torigoe, M. Suginome, Chem. Commun., 2014, 50, 6333.

5 M. L. McIntosh, C. M. Moore, T. B. Clark, Org. Lett., 2010, 12 1996.

6 K. Kubota, S. Osaki, M. Jin, H. Ito, Angew. Chem. Int. Ed. 2017 56,6646 .

7 The copper(I)-catalysed boryl substitution of alkyl halides, see: (a) H. Ito, K. Kubota, Org. Lett., 2012, 14, 890; (b) C.-T. Yang, Z.-Q. Zhang, H. Tajuddin, C.-C. Wu, J. Liang, J.-H. Liu, Y. Fu, M. Czyzewska, P. G. Steel, T. B. Marder, Angew. Chem. Int Ed. 2012, 51, 528.

8 The borylative cyclization of alkenyl halides, see: K. Kubota, E. Yamamoto, H. Ito, J. Am. Chem. Soc. 2013, 135, 2635.

9 A review of borylative cyclization reactions, see: E. Buñuel, D. J. Cárdenas, Eur. J. Org. Chem., 2016, 5446.

10 The recent reviews on copper(I)-catalysed borylation reactions, see: (a) D. Hemming, R. Fritzemeier, S. A. Westcott W. L. Santos, P. G. Steel, Chem. Soc. Rev. 2018, 47, 7477; (b) K. Semba, T. Fujihara, J. Terao, Y. Tsuji, Tetrahedron, 2015, 71, 2183.

11 The selected examples of copper(I)/Xantphos complexcatalysed borylation reactions, see: (a) H, Ito, C. Kawakami, M Sawamura, J. Am. Chem. Soc. 2005, 127, 16034; (b) H. Ito, Y. Sasaki, M. Sawamura, J. Am. Chem. Soc. 2008, 130, 15774.

12 The rate-acceleration effect by $\mathrm{MeOH}$ additive in the copper(I)-catalysed borylations has been reported, see: (a) S.
Mun, J-E. Lee, J. Yun, Org. Lett., 2006, 8, 4887; (b) K. Kubota, M. Jin, H. Ito, Organometallics, 2016, 35, 1376.

13 For the tosylate substrate (1e), full conversion of the substrate was observed even though the yield of the product was very low. Side reactions such as aldol condensation or polymerization might be occurred during the reaction.

14 A. Bonet, M. Odachowski, D. Leonori, S. Essafi, V. K. Aggarwal, Nat. Chem., 2014, 6, 584 